\section{THE INTERACTION BETWEEN PASSING} SHIPS.

NE of the prominent questions of the day in naval architecture circles is that of the influence of passing ships upon each other. It has been known for many years that such an influence exists between vessels in confined waters, canals, for example, and for such canals there are usually stringent regulations as to speed and manner of passing of ships. Such conditions are, of course, extreme, but the narrowness and shallowness of the canal, merely intensify a phenomenon which is present in deeper or broader waters, but not always apparent. tendency for it to cant in towards two; in the second position the forces are all tending to draw the two ovals together, there being throughout the body of water between them less pressure than exists on their outer sides. In the third case, oval one is subjected to forces tending to cant it towards or away from two, as the stern is in a field of pressure below normal on its nearer side, and the bow in a field of increased pressure on the inner side.

The extent and importance of these forces will depend on the lateral distance apart, on the bounding conditions of the fluid, and on the speeds, both absolute and relative, of the ovals. In order to give an indication of how greatly this influence is increased

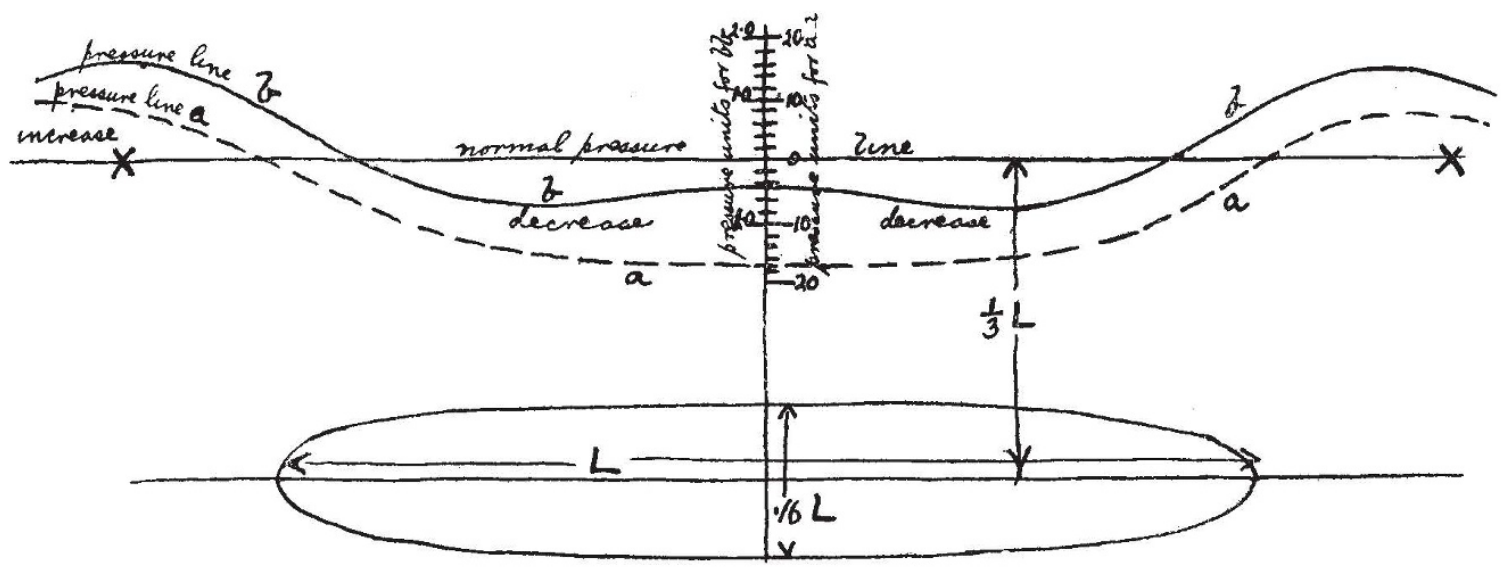

FIG, x,-Variation of pressure around an oval along the line $\mathrm{X} \mathrm{X}$.

A ship's form unfortunately cannot be expressed by any formula, and its stream lines cannot be easily calculated, but by considering the case of two ovals formed by "sources and sinks," we can get a rational idea of the character and variation of the forces which come into play. The equation for the pressure at any point in the fluid surrounding an oval is given by :-

$$
-\frac{\not p}{w}=\frac{v^{2} f}{2 g}\left[\left(\frac{\cos \phi_{1}}{r_{1}^{2}}-\frac{\cos \phi_{2}}{r_{2}^{2}}\right)+\frac{f}{4}\left(\frac{\mathrm{I}}{r_{1}^{4}}+\frac{\mathrm{I}}{r_{2}^{4}}-\frac{2 \cos \left(\phi_{1}+\phi_{2}\right)}{r_{1}^{2} r_{2}^{2}}\right)\right]
$$

where $r_{1}, \phi_{1}$ and $r_{2}, \phi_{2}$ are distance and angle from source and sink respectively, and $f$ varies with the distance between source and sinl and length of major axis, and $v^{2}$ is the relative velocity of fluid and oval.

The line $b \quad b$ in Fig. I shows the variations of the pressure from the normal, along a line distant onethird the length from the centre line, and it can be seen from this that, speaking generally, there exist at each end of such an oval fields of increased pressure, and that the space between them is a region of diminished pressure.

If two such ovals are moving in the fluid, it can be readily seen that the variations of pressure due to one will modify the pressures due to the other, and that the pressure conditions on the sides of the ovals nearer to each other are different from those on the outer sides.

In Fig. 2 the ovals are shown in three positions relative to each other, and the arrows at each end of oval one show the motion which the forces due to interference tend to set up. If one is overtaking two, in the first position shown, there will be a strong No. 2 I96, vOL. 88 ] when a body moves from deep to shallow water, the curve $a a$ has been drawn in Fig. I. This shows the variation of pressure for a plane oval (i.e. with twodimensional flow), having the same axes as the oval for which curve $b \quad b$ has been drawn, and it will be noticed that the scale of $a a$ is one-tenth that of $b b$.

Such general reasoning, however, although showing the nature of "interference," does not give a measure of the forces involved with actual ship forms under similar conditions, and to obtain this experiments must be made with models in water of different depths.

Experiments conducted in 1898 in a German canal

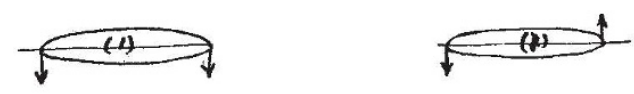

FIG. 2.-Action between passing ovals.

with barges having a sectional area approximately onethird the sectional area of the canal, showed a region of considerable excess pressure in front and at the rear of the barge, and on the bank for the whole length of the barge a remarkably strong negative current or diminution of pressure.

The experiments made by Naval Constructor D. W. Taylor in the Washington Tank, throw a considerable light on the problem. The ship-shaped models used were of the same length and were run at an average speed corresponding to $13^{*} 5$ knots for 500 -feet ships.

The results of the experiments show that in very deep water such ships do not begin to influence each 
other appreciably until their distance apart is less than 0.8 of their length, and that this influence is becoming very noticeable when the distance apart is $0^{\circ} 6$ of their length. It was also found that, with the models in any given position, the forces involved varied as the resistance of the models, i.e. for these speeds roughly with the square of the velocity as theory would lead us to expect.

The variations of the forces as one model was moved to varying fore and aft positions relative to the other (keeping the lateral distance the same) showed the very strong tendency which any model had to cant into the stern of the other model which it was overtaking, how this tendency to cant changed, as the models were brought abreast each other, to a strong: sheer of each model towards the other, and, finally, when one model was shifted so that its bow was well forward of the bow of the other, it had a strong desire to cant away from the latter. This is all much the same as the consideration of our two ovals has led us to expect, and goes to show that passing vessels, even in deep water, are liable to exert strong forces upon each other. If they are moving at approximately equal speeds in the same direction, i.e. if the forces are maintained for a considerable time, then these forces will tend to produce erratic movements of the ships, requiring careful navigation if a collision is to be avoided.

No experiments have been made up to the present to test this suction or interference in shallow water. except those made recently at the National Experiment Tank at Teddington in connection with the Hawke and Olympic collision; but the general reasoning already given is good ground for supposing that such influence would be greatly magnified as a vessel passed from deep to shallow water.

\section{THE CENTRAL EUROPE EARTHQUAKE,} NOVEMBER 16, igr.

$\mathrm{N}$ the night of November I6, at 10.25 , western Germany, eastern France, and Switzerland were rudely shaken by an earthquake of exceptional in- earthquake was marked by ruin from Magdeburg to Berlin. Everywhere terror-stricken people "rushed" from their houses, and at Ebingen 500 of its inhabitants gathered round a fire during the night and recounted their weird experiences.

It is difficult to reconcile these descriptions of widespread ruin with the fact that there does not appear to have been a single casualty. One thing about which we can be certain is that the earthquake was felt eastward to Erfurth, westwards to Nancy, and southwards to Milan. At least $\mathrm{I} 7,000$ square miles of Central Europe received a shaking perceptible to the greater number of its inhabitants. Outside this area it was recorded by many seismographs. Whether the disturbance was or was not recorded in very distant places largely depends upon the character of the instrument employed to record teleseismic motion. Experience has shown that seismographs recording photographically pick up these effects at greater distances from an epicentral area than those which register mechanically.

The accompanying seismogram of east and west motion, as recorded in the Isle of Wight, shows that the disturbance commenced at $9 \mathrm{~h} .27 \mathrm{~m}$. 30s., and reached a maximum two minutes later. The inference from this is that the origin was 5 degrees or 300 geographical miles distant. That it was a near earthquake is also indicated by the rapidity of the vibrations. At the distance indicated we reach the upper part of the Rhine Valley, a district from Frankfort, through Bâle to Constance, well known to seismologists as an earthquake-producing region. In a popular sense the upper part of this is a valley, but from the manner in which it originated it is sometimes referred to by geologists as a graben, or piece of territory that has fallen downwards between two faults. In this instance one of these faults borders the Vosges and the other the Black Forest. It is a tectonic displacement along which adjustments from time to time have taken place, each of which represented a relief of strain and was accompanied by a shaking. One well-known paper solemnly informs its readers that this earthquake was of Teutonic origin,

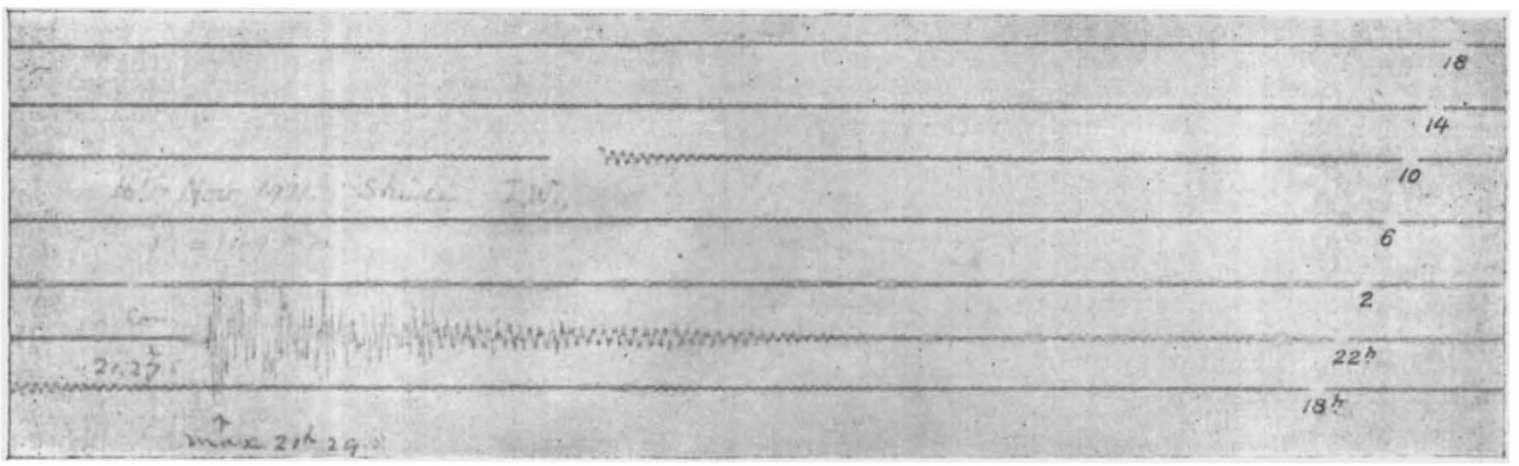

tensity. At Frankfort-on-Main houses were cracked. In Freiburg, Stuttgart, Munich, Mülhausen, and in other towns, chimneys and roofs were damaged. The valley of the Upper Rhine was shaken throughout its length. At Constance two colossal statues fell from the Post Office upon the pavement. According to reports in the daily papers, walls were split, church spires were wrecked, roofs were shattered, people were "thrown out of their beds," telephone and telegraph communications were destroyed, and the path of the vo. 2 I96, vol. 88] and, considering the country in which it was made, the statement may be regarded as correct.

At present it cannot be said with certainty that this disturbance originated from the chief of these tectonic lines or from one of their numerous offshoots. To the right and the left of the Rhine Valley the country is cracked through and through with many minor fractures, a sudden movement on any one of which might be capable of producing all that has been observed.
J. Milne. 